\title{
For Better Fat Graft Outcome in Soft Tissue Augmentation: Systematic Review and Meta-Analysis
}

\author{
Jin Bin Kim, Han Byeol Jin, \\ Ji Hwan Son, Jee Hyeok Chung \\ Department of Plastic and Reconstructive \\ Surgery, Myongji Hospital, Goyang, Korea
}

No potential conflict of interest relevant to this article was reported.

\begin{abstract}
Background Autologous fat grafts are widely used in plastic surgery, but they have the disadvantage of unpredictability due to variable resorption. This meta-analysis examined the literature on the survival rate of autologous fat grafts using objective markers, and investigated the factors that affected the survival rate.

Methods The reviewers searched the PubMed, EMBASE, and Cochrane Library databases from January 2001 to December 2017. A meta-analysis was performed to estimate fat graft survival and to identify variables that influenced the survival rate.

Results A total of 27 studies (1,066 cases) were included in the meta-analysis. The mean survival rate of grafted fat was $56.5 \%$. The survival rate was significantly higher for cellassisted lipotransfer ( $C A L)$ than for non-CAL (62\% vs. 53.4\%; $P=0.015)$. The survival rate for procedures performed to correct lipoatrophy was higher than that of procedures performed for other purposes ( $64.6 \% ; \mathrm{P}=0.014)$, and was significantly higher in patients who underwent breast pre-expansion using the BRAVA device (66.2\% vs. 50.35\%; $P=0.001$ ). There were no significant differences in the survival rate according to the recipient site, harvesting method, or refinement method.

Conclusions Fat transplantation showed a varying survival rate, with an average of $56 \%$. In patients who underwent CAL or breast pre-expansion with the BRAVA device, the survival rate of transplanted fat was higher than in their counterparts, supporting the use of these techniques in fat transplantation.
\end{abstract}

Keywords Adult stem cells, Analysis of variance, Autografts

\section{INTRODUCTION}

Autologous fat grafting, also referred to as lipofilling, is widely used in plastic surgery. Although it is mostly utilized to correct tissue defects after cancer surgery or trauma, cosmetic breast augmentation, facial contouring [1], and facial atrophy in human immunodeficiency virus patients receiving antiretroviral therapy, some preliminary studies have also reported its effectiveness in autologous

Received: May 9, 2018 Revised: Jul 13, 2018 Accepted: Jul 16, 2018 Correspondence: Jee Hyeok Chung Department of Plastic and Reconstructive Surgery, Myongji Hospital, 55 Hwasu-ro 14beon-gil, Deogyang-gu, Goyang 10475, Korea. E-mail: gabriel@mjh.or.kr

Copyright @ 2018 The Korean Society for Aesthetic Plastic Surgery.

This is an Open Access article distributed under the terms of the Creative Commons Attribution Non-Commercial License (http://creativecommons.org/licenses/by-nc/4.0/) which permits unrestricted non-commercial use, distribution, and reproduction in any medium, provided the original work is properly cited. $\quad$ www.e-aaps.org free-fat transfer for diabetic foot ulcers [2], pressure sores [3], and radiotherapy scars [4].

Autologous fat grafting is host-compatible, non-immunogenic, and inexpensive, and also allows easy and repeated harvesting [5]. Moreover, because of its low complication rate, without the foreign body reactions that occur with other materials, autologous fat is considered to be an ideal soft tissue filler. However, the unpredictability of long-term graft retention due to the variable resorption rate of autologous fat has always been a disadvantage of free fat transfer; with resorption rates ranging between $20 \%$ and $80 \%$ [6-9], some cases have required multiple procedures.

Various factors affect the survival of a fat graft. Hypoxia or tissue ischemia due to the lack of adequate neovascularization has been presented as a mechanism that lowers the survival rate. Although various methods have been suggested to improve the rate, the optimal technology for handling adipose tissue remains controversial. One technique is cell-assisted lipotransfer (CAL), reported by Mat- 
sumoto et al. [10] in 2006. With CAL, an improved survival rate is expected as a result of supplementation with cultured adipose-derived stem cells (ASCs) or stromal vascular fraction (SVF), which includes all cell lines in the fat tissue, except adipocytes. Since Yoshimura et al. [11] first performed CAL with SVF on humans in 2008, many studies have proven its efficacy.

Subsequent to a report describing Coleman's method and CAL, numerous studies evaluating the efficacy of these methods have been published. However, in most of those studies, the patient and/ or surgeon performed an evaluation using photographs or subjective markers of satisfaction [7,12]. With recent advances in imaging, it has become possible to objectively evaluate the survival rate of autologous fat grafts. A meta-analysis was performed of studies that objectively analyzed the survival rate of autologous fat grafts, to investigate the following questions:

1. Does CAL, which adds ASCs, improve the survival rate in contrast to using conventional fat grafts [13]?

2. As the face has better circulation, and less fat is injected into the face on average, is the survival rate higher in the face than in other body regions $[7,14,15]$ ?

3. Is the survival rate lower in the reconstruction of defects after cancer excision [16-18] or in patients with underlying diseases [19] of the soft and hard tissues, such as Parry-Romberg syndrome [20] and craniofacial microsomia, than in patients receiving fat grafts for aesthetic purposes?

4. Minimally traumatic procedures are necessary for viability in lipoaspiration; does the survival rate differ depending on the harvesting and refinement methods [21,22]?

5. Does expanding the breasts with a BRAVA device (Brava LLC, Miami, FL, USA) before fat grafting increase the survival rate [23]?

\section{METHODS}

This study was performed according to the Preferred Reporting Items for Systematic Reviews and Meta-Analysis (PRISMA) statement [24].

\section{Search strategy}

Two independent reviewers (Jin Bin Kim, Han Byeol Jin), searched the PubMed, EMBASE, and Cochrane Library electronic databases for articles published between January 2001 and December 2017 using the following keywords: "Fat graft" or "Fat grafting" or "Fat transplant" or "Fat transplantation" or "Fat transfer" or "Fat augmentation" or "Fat injection" or "Lipoinjection" or "Lipotransfer" or "Lipofilling" or "Lipograft" or "Autologous fat" or "Autogenous fat". There were no limits to the search; if articles in a foreign language were identified, every effort was made to obtain an English version or to translate the articles.

\section{Inclusion and exclusion criteria}

The inclusion criteria were as follows: 1) All articles related to fat grafting performed on humans for the purpose of soft tissue reconstruction or augmentation, regardless of age or sex; 2) Studies that used objective devices to perform volumetric evaluation of the efficacy of fat grafting; 3) Studies that evaluated survival rates at least 3 months after surgery; 4) Inclusion of at least 5 cases.

The exclusion criteria were as follows: 1) Intact fat tissue obtained by en bloc excision was transferred instead of lipoaspirate; 2) Efficacy was evaluated based on a photographic analysis or subjective satisfaction levels; 3) Insufficient data were available for the metaanalysis; 4) Survival rates were evaluated within 3 months after surgery.

\section{Study selection and quality assessment}

Two independent reviewers evaluated the eligibility of all studies identified using the predetermined inclusion and exclusion criteria. After eliminating duplicates, articles that were obviously irrelevant based on a review of the title and abstract were also eliminated. After adding eligible articles identified from reference lists and the gray literature, full-text screening was performed. After the full-text review, articles to be included in the systematic review and meta-analysis were selected. Any disagreement between the 2 reviewers was resolved by discussion and consensus, and all authors agreed upon the final list of included studies.

Next, 2 independent reviewers assessed the level of evidence and study design of the selected studies. The level of evidence for each article was assessed using the standardized reporting scheme provided by the Oxford Centre for Evidence-based Medicine 2011 guideline [25].

\section{Data extraction}

Two reviewers independently performed data extraction of the following items using a pre-designed data collection form.

1. Baseline study data (author[s], publication year, level of evidence)

2. Description of sample (sample number, patient age, body mass index, purpose of procedure, recipient site)

3. Procedural details (donor sites, method of harvesting and refinement, CAL or conventional lipograft, injected volume, source of stem cells, use of a BRAVA device)

4. Results (volumetric evaluation method, fat graft survival rate, number of multiple procedures)

No assumptions were made about the methods used if they were not reported, but any appendices, other articles, or any books referenced were reviewed in order to extract relevant data. Methodological factors not reported either directly or indirectly were presented as "unspecified." 


\section{Statistical analysis and validity assessment}

We used the comprehensive meta-analysis software (version 2.2.064; Biostat Inc., Englewood, NJ, USA) for this meta-analysis. Twentyseven studies with sufficient and objective quantitative data were included in the meta-analysis. We assessed the mean survival rate of fat grafts and investigated the variables that influenced fat graft survival through subgroup analyses.

To assess heterogeneity among individual studies, the Cochrane Q statistic and $\mathrm{I}^{2}$ values were calculated [26]. $\mathrm{I}^{2}$ indicates the percentage of true variance relative to total variance. $\mathrm{I}^{2}$ values $<25 \%$ can be interpreted as indicating low heterogeneity, whereas $50 \%$ represents moderate heterogeneity and values $\geq 75 \%$ represent high heterogeneity. Publication bias was verified visually with a funnel plot and statistically with the Egger regression test. The reli- ability of this study was then evaluated by calculating the stability factor (classic fail-safe N).

As the studies included in the analysis were conducted by different researchers using their own methods, it could not be assumed that the effect size of the study population would be the same. Therefore, a random-effects model was used to estimate the effect size. The results are shown in a forest plot with $95 \%$ confidence intervals (CIs). P-values $<0.05$ were considered to indicate statistical significance.

\section{RESULTS}

\section{Literature search}

A total of 21,741 articles were identified from the databases using

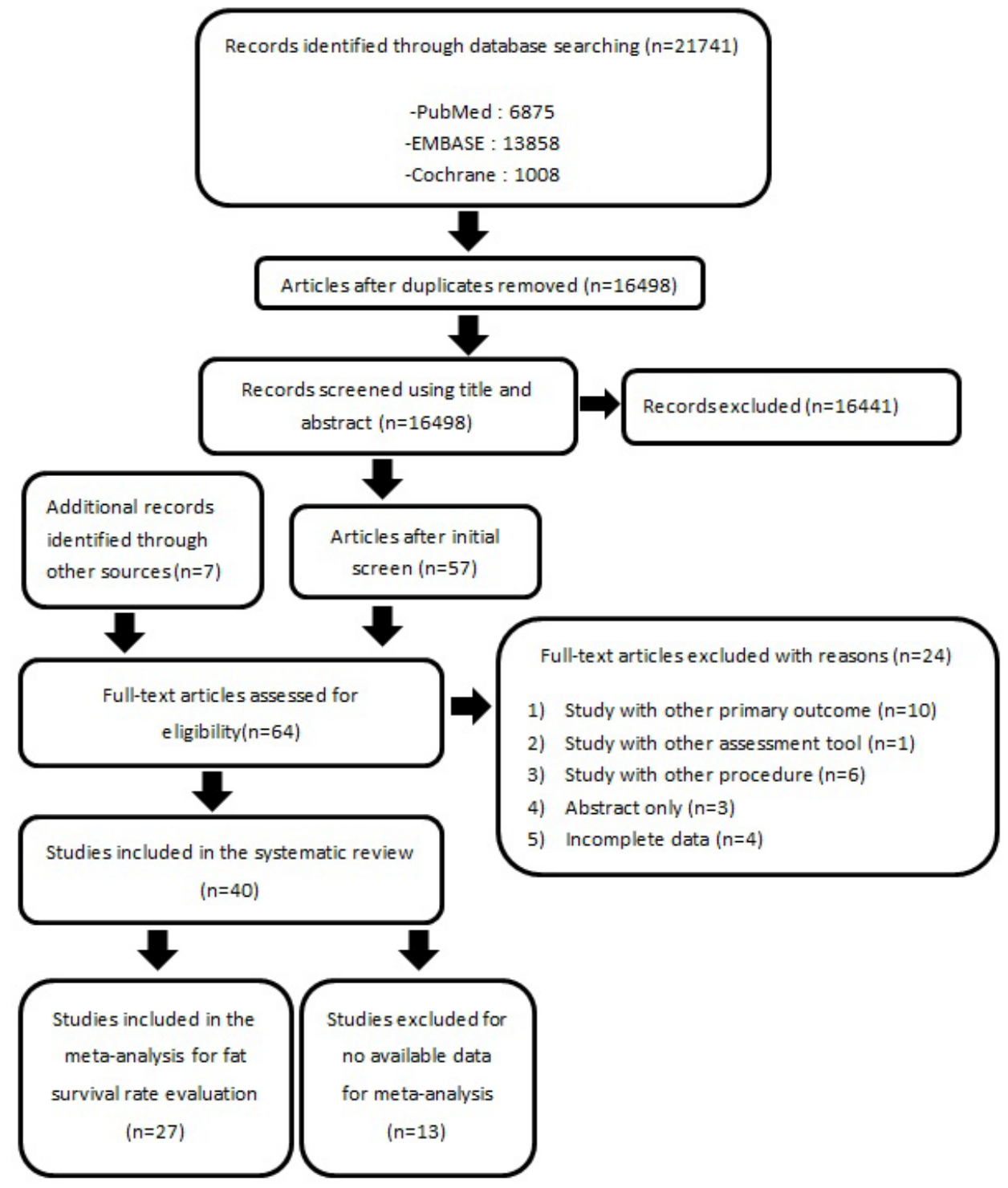

Fig. 1. Flow chart of study selection. 
the predefined keywords. After eliminating duplicates, an initial screening was performed of the remaining 16,498 articles by reading the titles and abstracts. As a result, 57 articles were selected for further screening. Seven additional articles were added based on the reference lists and gray literature, and a full-text review was subsequently performed of 64 articles. Among these, 40 articles were included in the systematic review, and 27 were included in the meta-analysis for assessing the fat graft survival rate.

All 40 studies evaluated the survival rate of transplanted fat using objective imaging tools. However, 13 of these studies only presented average survival rates and did not report the standard deviation (SD), making it impossible to compare the studies, and these were excluded from the meta-analysis (Fig. 1).

\section{Characteristics of included studies}

A total of 40 studies, covering a total of 2,034 cases of fat grafting, were included in the systematic review, and their characteristics are shown in Table 1. There were 4 randomized controlled trials, 19 cohort studies, and 17 case series.

In terms of the recipient sites, 22 studies analyzed procedures performed on the breasts, 17 on the face, and 1 on the arm. For radiological analysis of the survival rate of the fat grafts, 17 studies conducted magnetic resonance imaging, 14 conducted 3-dimensional scans, 7 conducted computed tomography, and 2 conducted ultrasound.

Table 2 presents the details of the fat graft procedures. CAL was performed in 17 studies; only 2 studies used cultured ASCs, whereas 15 used SVF. For SVF isolation, 9 studies manually isolated the cells, whereas 6 employed automatic isolation. Among these 40 studies, 27 used manual syringe aspiration for fat harvesting and 9 used a liposuction machine for lipoaspirate harvesting, whereas 4 did not present data on the harvesting method. In most of these studies (32 articles), centrifugation was used as the lipoaspirate refinement method. A total of 22 articles evaluated the breast as the recipient site, among which pre-expansion using the BRAVA device was performed in 7 studies.

\section{Validity assessment}

Homogeneity of the effect size across studies was rejected, with a Q-value $>\mathrm{df}(\mathrm{Q})$ and a P-value $<0.001$, and the heterogeneity assessment results showed an $\mathrm{I}^{2}$ value of $99.4 \%$, indicating a significant level of heterogeneity across studies [27].

The funnel plot (Fig. 2) demonstrated asymmetry around the mean, with all studies with high standard errors (small studies with small sample sizes) that were included in the meta-analysis distributed to the right of the mean. This plot indicated that the present study had a small-study effect and publication bias, and the presence of this publication bias was statistically confirmed with the Egger regression test $(\mathrm{P}<0.001)$. However, the fail-safe $\mathrm{N}$, which represents the coefficient of stability, was found to be 4,445 . Despite bias, the study was still reliable, as it included most studies reporting the survival rates of fat grafts using objective indicators.

\section{Efficacy assessment}

Efficacy assessment focused on the fat graft survival rate, which was defined as the percentage of mean volume gained to mean volume injected. Fig. 3 shows pooled estimates of the fat graft survival rate. The mean fat graft survival rate determined from the studies included in the analysis was 56.5\% (95\% CI, 53.2-59.8\%).

\section{Subgroup analyses (moderator analyses)}

In order to investigate factors influencing the fat graft survival rate, a meta-analysis of variance was conducted on the procedure method, recipient site, purpose, harvesting method for lipoaspiration, and refinement method.

Additional analyses were performed to investigate which subgroups showed the highest survival rates according to the procedure and recipient site.

\section{Assessment based on procedure method}

The CAL group had a mean fat graft survival rate of $62.0 \%$ (95\% CI, 56.5-67.5\%), which was statistically significantly higher than the rate of $53.4 \%$ (95\% CI, 49.2-57.6\%) in the non-CAL (NCAL) group $(\mathrm{P}=0.015)$. The CAL and NCAL groups had $\mathrm{I}^{2}$ values of $99.4 \%$ and $99.4 \%$, respectively, with the values remaining high in the subgroup analysis (Fig. 4A).

\section{Assessment based on recipient site}

The mean survival rate in the arm, breast, and face was 48.7\% (95\% CI, 29.2-68.3\%), 55.8\% (95\% CI, 49.2-62.4\%), and 58.1\% (95\% CI, 51.8-64.5\%), respectively. Although the differences in the survival rates ranged from $2 \%$ to $10 \%$ between subgroups, these differences were not statistically significant $(\mathrm{P}=0.639)$. Even when divided into groups by recipient site, the $\mathrm{I}^{2}$ value was $99 \%$ in all 3 groups, showing very high heterogeneity (Fig. 4B).

\section{Assessment based on the purpose of the fat graft}

Studies were grouped into 4 categories depending on the purpose of the fat graft: 1) reconstruction of tissue defects after cancer excision; 2) aesthetic purposes; 3) correction of lipoatrophic conditions arising from hereditary or acquired factors, such as Parry-Romberg syndrome, craniofacial microsomia, and facial clefts; and 4) mixed purposes (i.e., different purposes that could not be categorized into a coherent group).

The cancer reconstruction group had a mean survival rate of 55.5\% (95\% CI, 40.8-70.1\%), whereas the aesthetic group had a mean survival rate of $53.8 \%$ (95\% CI, $47.8-59.7 \%)$. The fat graft survival rate in the mixed purpose group was $46.7 \%$ (95\% CI, 37.1$56.3 \%)$. The group undergoing correction of lipoatrophy showed the highest fat graft survival rate (64.6\%; 95\% CI, 58.0-71.1\%), and 


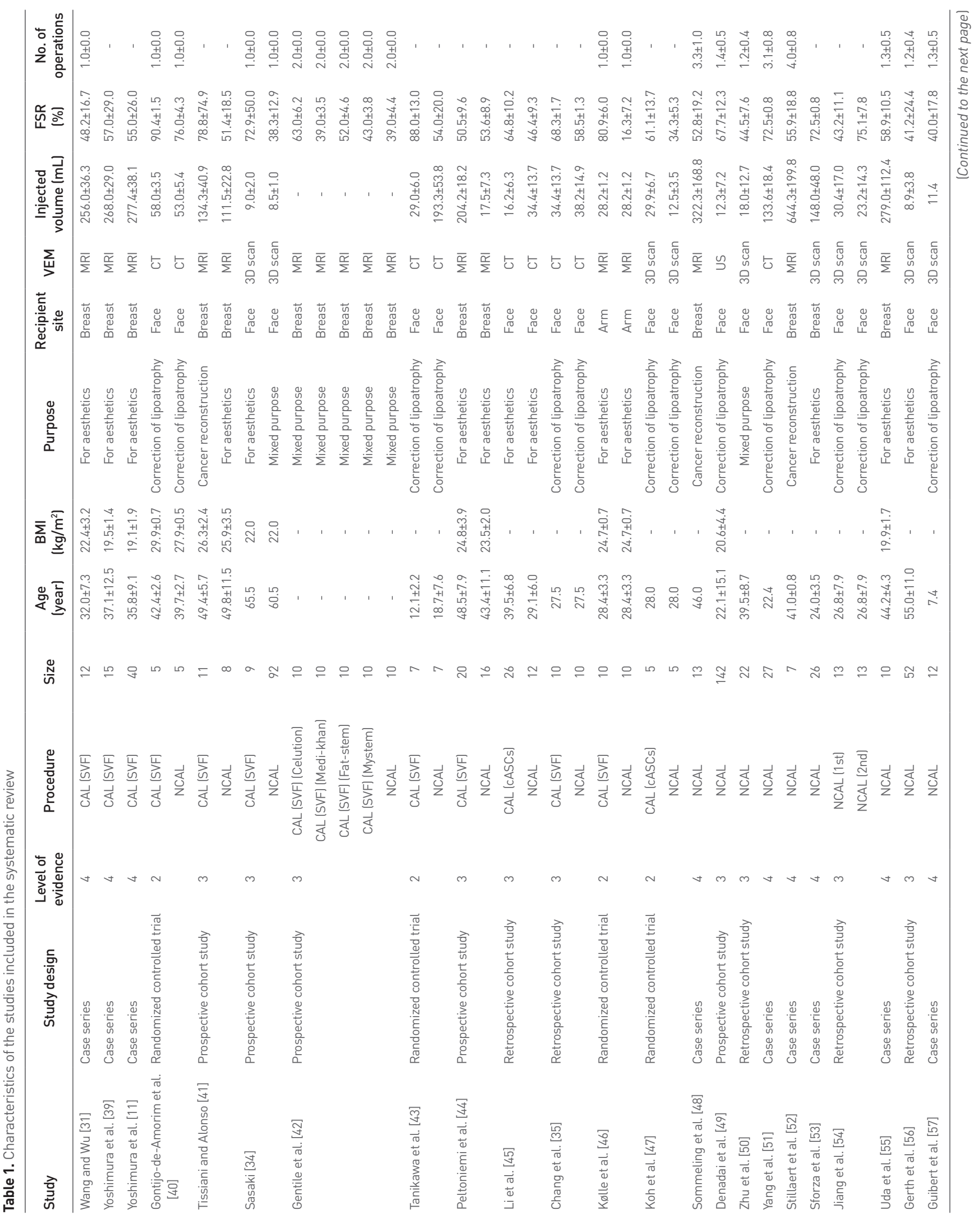




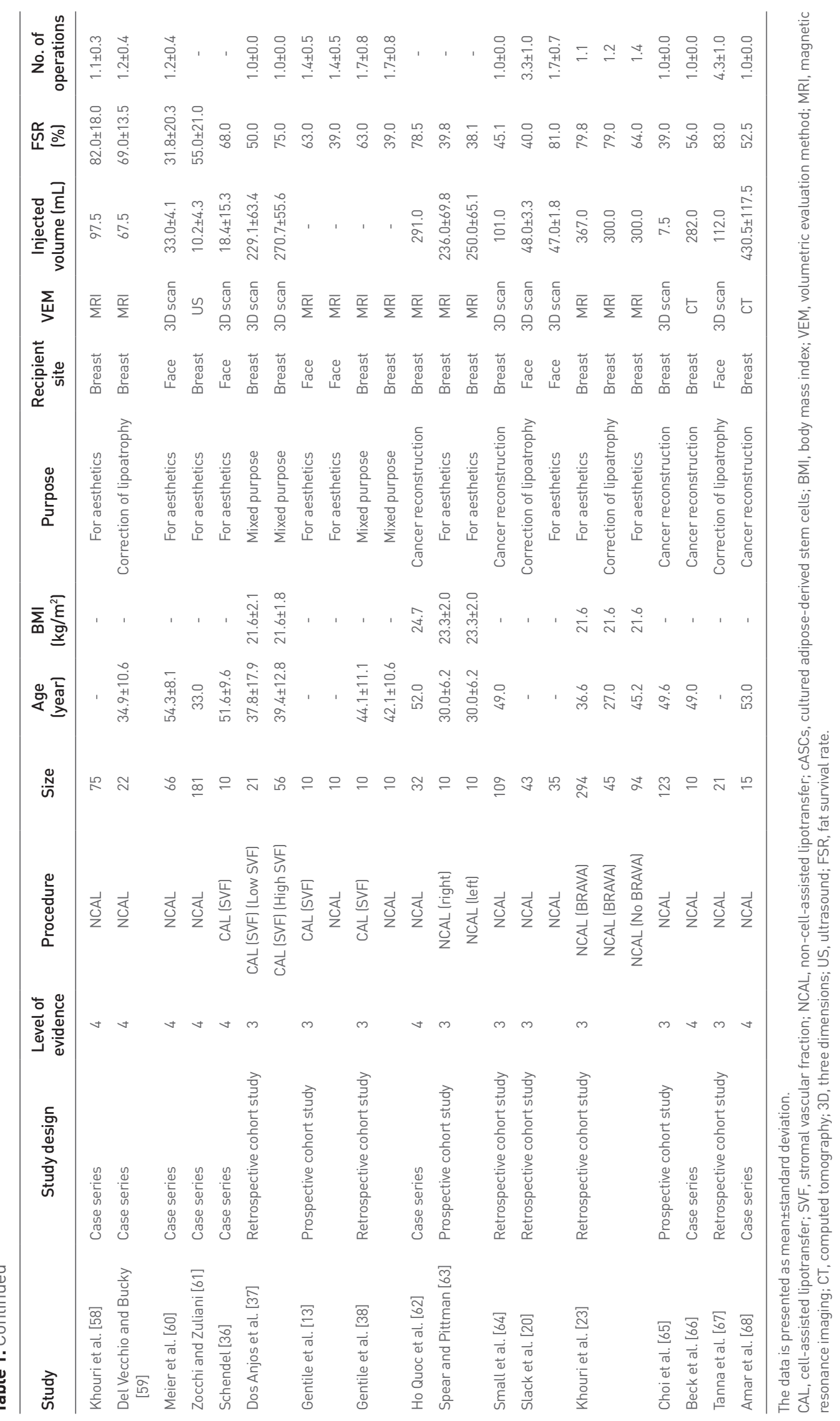


Table 2. Details of the fat graft procedures

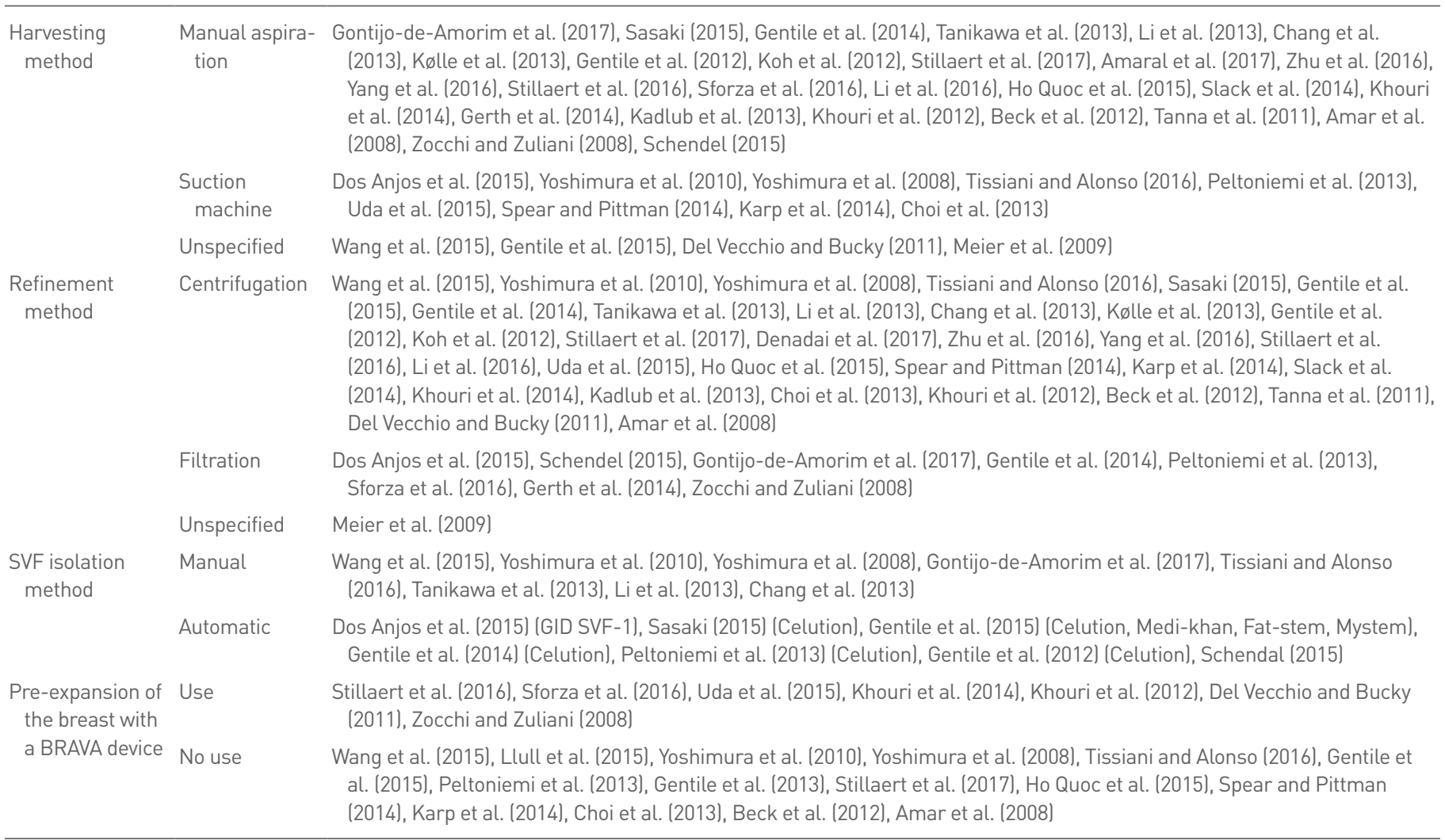

SVF, stromal vascular fraction.

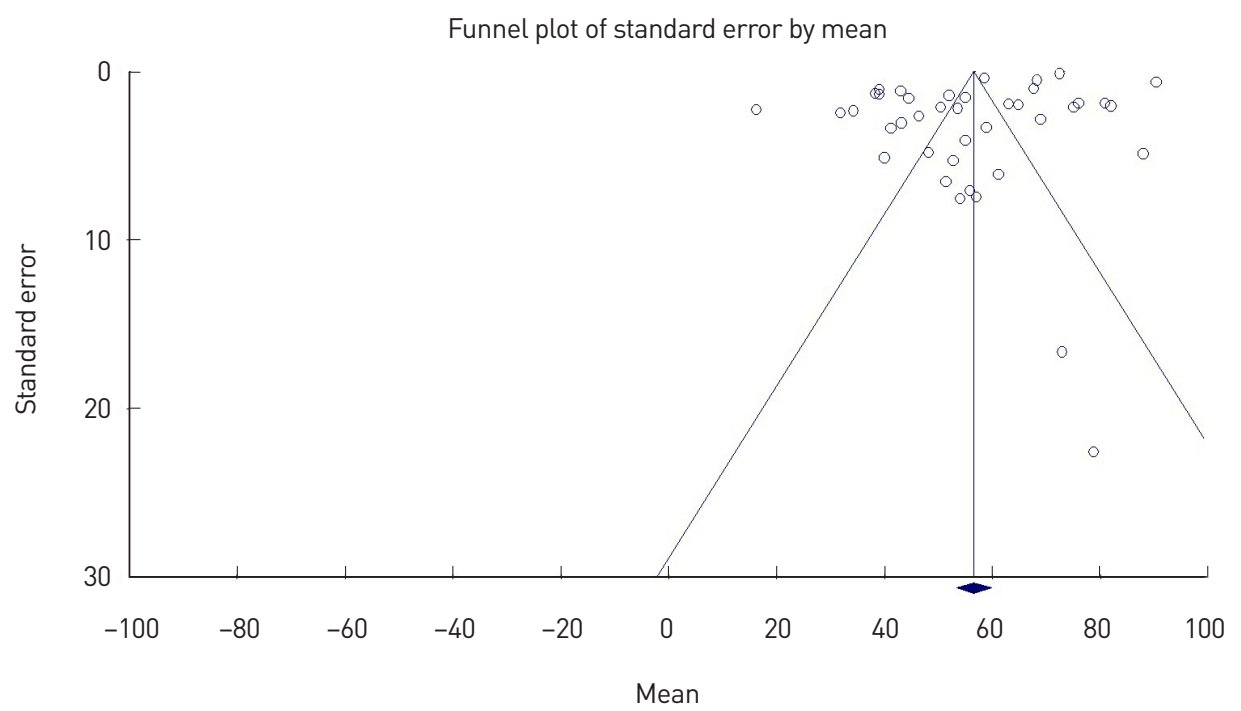

Fig. 2. Funnel plot for publication bias. The asymmetry of the articles on the lower right side of the mean indicates that the sample size was small, but studies with large effect sizes were included.

the differences between groups were statistically significant $(\mathrm{P}=0.014)$. In homogeneity testing, the cancer reconstruction group had a $\mathrm{Q}$ value of $1.481, \mathrm{df}(\mathrm{Q})=3$, and $\mathrm{P}=0.686$; thus, no significant relationship was found between the difference in survival rates report- ed in studies and a lack of heterogeneity. In other groups, considerable heterogeneity (99\%) was observed in the survival rates between studies (Fig. 4C). 


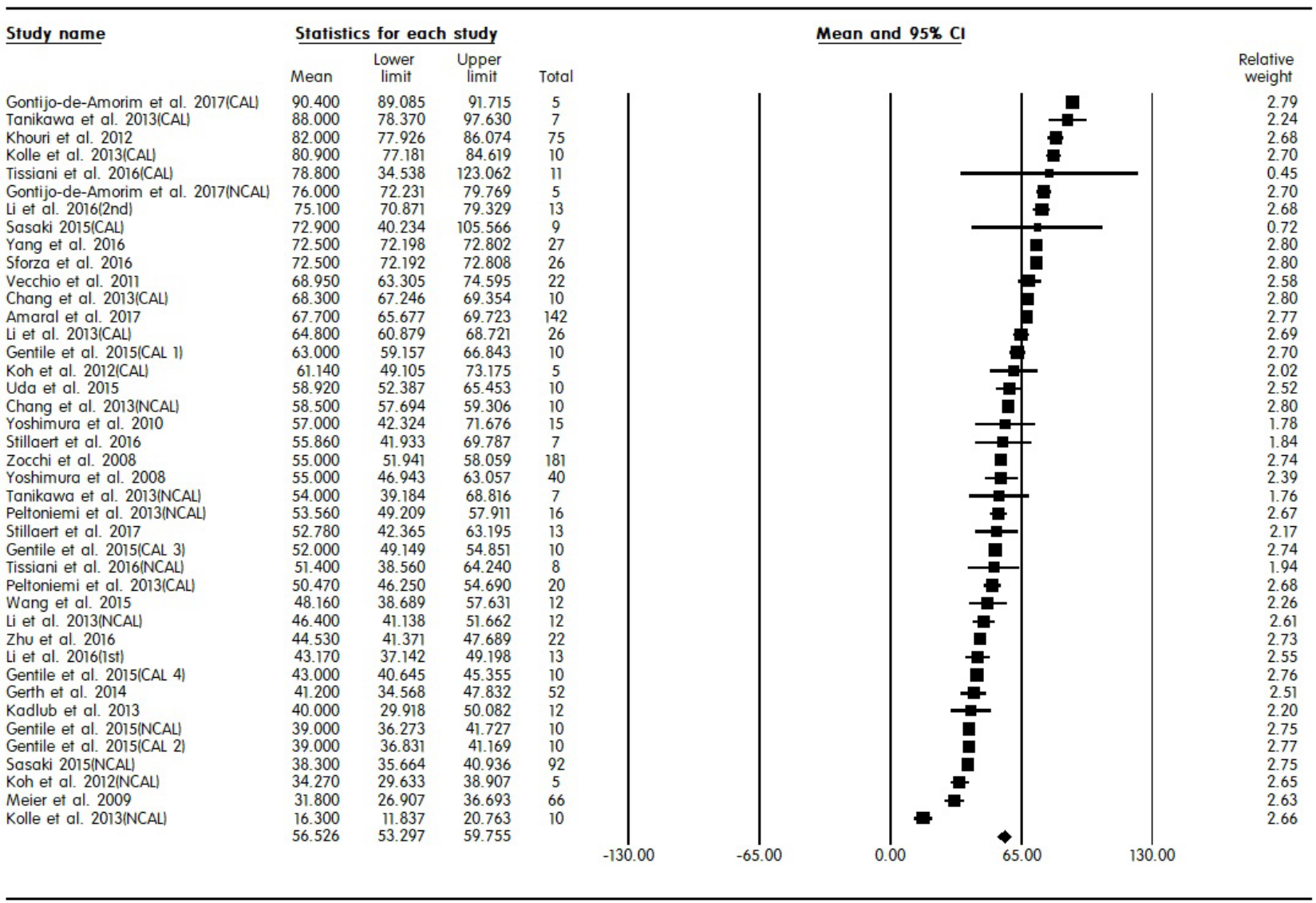

Pooled estimates

Fig. 3. Pooled estimates of the fat survival rate. A random-effects model was applied because the effect size of the population could not be assumed to be the same. $\mathrm{Cl}$, confidence interval.

\section{Assessment based on the harvesting method and refinement method}

The manual aspiration group had a mean survival rate of $59.8 \%$ (95\% CI, 56.4-63.1\%), the liposuction machine group had a rate of $54.9 \%$ (95\% CI, 47.6-62.1\%), and the unspecified group had a rate of $47.9 \%$ (95\% CI, 42.1-53.8\%); the differences between the groups were statistically significant $(\mathrm{P}=0.002)$. However, when only the manual aspiration and liposuction machine groups were analyzed, the difference was not statistically significant $(\mathrm{P}=0.228)$. Heterogeneity testing showed consistent survival rates in the liposuction machine group $\left(\mathrm{Q}=6.335 ; \mathrm{df}[\mathrm{Q}]=6 ; \mathrm{P}=0.387 ; \mathrm{I}^{2}=5.281\right)$.

Depending on the preparation process for aspirated fat, the cases were divided into centrifugation, filtration, and unspecified groups. The mean survival rates in the centrifugation, filtration, and unspecified groups were 55.9\% (95\% CI, 51.1-60.7\%), 63.0\% (95\% CI, 53.0-72.9\%) and 31.8\% (95\% CI, 5.3-58.3\%), respectively, and the differences were not statistically significant $(\mathrm{P}=0.08)$.

\section{Additional analysis}

In an additional analysis of CAL classified according to the purpose of the procedure, the cancer reconstruction group and the correction of lipoatrophy group showed survival rates of $78.8 \%$ (95\% CI, 27.1-130.5\%) and 77.3\% (95\% CI, 63.5-91.2\%), respectively; these survival rates were significantly higher than those of the aesthetic group (60.6\%; 95\% CI, 49.7-71.6\%; P=0.034). In the analysis of recipient sites, the face had a significantly higher survival rate $(74.6 \%$; 95\% CI, 63.4-85.8\%) than the breast $(51.6 \%$; 95\% $\mathrm{CI}, 42.6-60.6 \% ; \mathrm{P}=0.002)$. In the analysis of harvesting methods, the manual aspiration group showed a significantly higher survival rate $(75.6 \%$; 95\% CI, 65.6-85.7\%) than the liposuction machine group (55.9\%; 95\% CI, 41.4-70.5\%; $\mathrm{P}=0.049)$. No significant difference was found between the refinement methods.

In the conventional fat graft group, there was no significant difference in the survival rate of fat grafts according to the purpose, recipient site, harvesting method, or refinement method.

Additional analysis by recipient site showed a significantly higher survival rate in the face group when CAL was performed (74.6\%; 95\% CI, $63.1-86.1 \%$ vs. $51.9 \%$; $95 \%$ CI, $44.8-58.9 \%$; $<<0.001$ ), as well as a higher survival rate in the correction of lipoatrophy group than in the aesthetic group (64.3\%; 95\% CI, 58.5-70.1\% vs. $46.1 \%$; 95\% CI, 37.2-55.0\%; $\mathrm{P}<0.001)$. In the breast recipient group, there 
Moderator : Procedure

\begin{tabular}{|c|c|c|c|c|c|c|c|c|}
\hline \multirow{2}{*}{$\begin{array}{l}\text { Group by } \\
\text { Procedure }\end{array}$} & \multirow[t]{2}{*}{ Study name } & & & \multicolumn{5}{|c|}{ Mean and $95 \% \mathrm{Cl}$} \\
\hline & & $\begin{array}{l}\text { Lower } \\
\text { limit }\end{array}$ & $\begin{array}{c}\text { Upper } \\
\text { limit }\end{array}$ & & & & & \\
\hline CAL & 61.991 & 56.479 & 67.502 & & & & 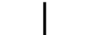 & | \\
\hline NCAL & 53.385 & 49.203 & 57.566 & & & & & \\
\hline \multirow[t]{2}{*}{ Overall } & 56.529 & 53.197 & 59.860 & & & & & \\
\hline & & & & -80.00 & -40.00 & 0.00 & 40.00 & 80.00 \\
\hline
\end{tabular}

Pooled estimates

Moderator : Recipient

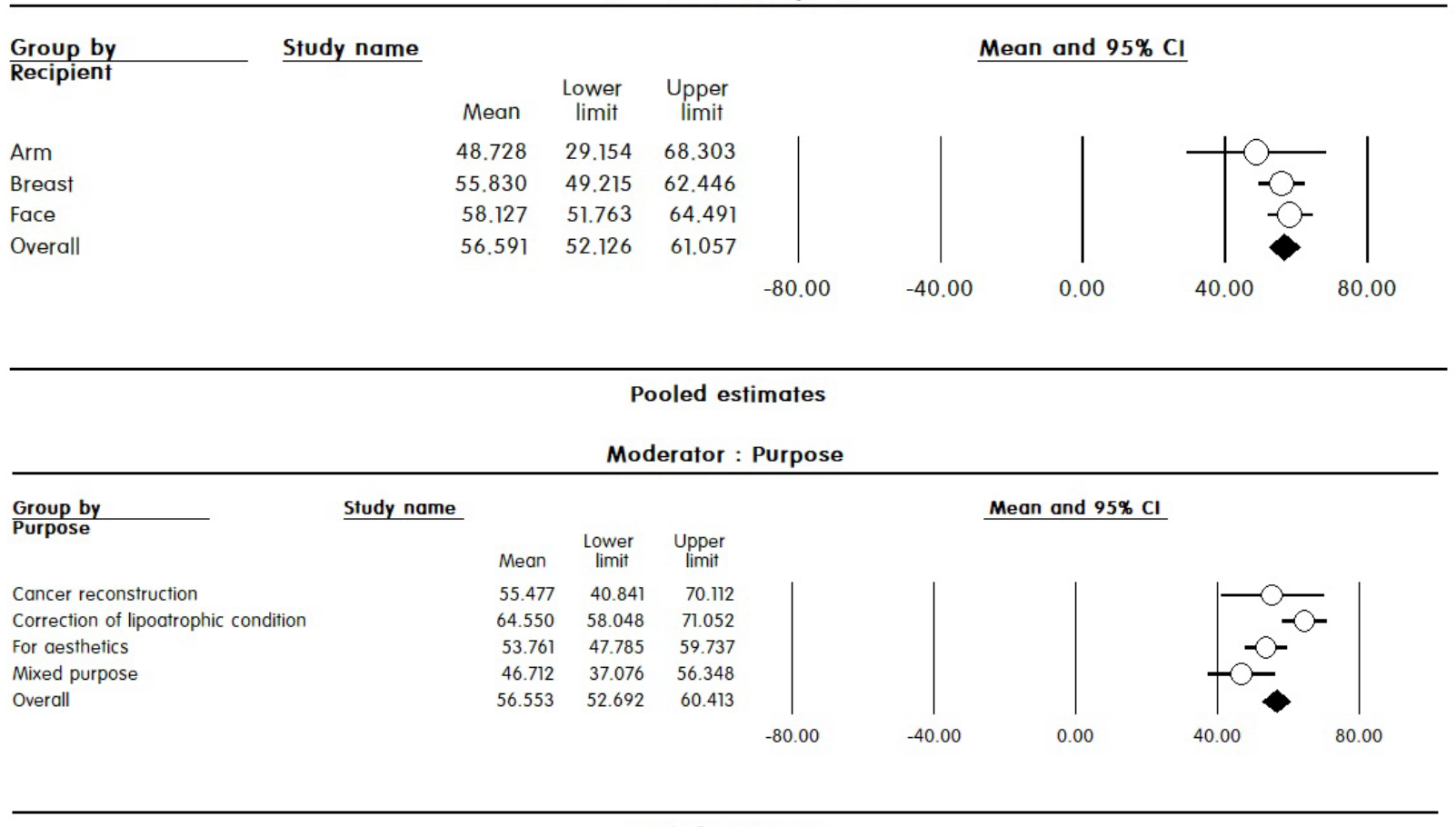

Fig. 4. Pooled estimates after subgroup analysis. (A) Subgroup analysis according to the procedure method. Pooled estimates of fat survival rates for the cell-assisted lipotransfer (CAL) and non-cell-assisted lipotransfer (NCAL) groups (P=0.015). (B) Subgroup analysis according to the recipient site. (C) Subgroup analysis according to the purpose of the procedure $(\mathrm{P}=0.014)$. $\mathrm{Cl}$, confidence interval.

Moderator : BRAVA device

\begin{tabular}{|c|c|c|c|c|c|c|c|c|}
\hline \multirow{2}{*}{$\begin{array}{l}\text { Group by } \\
\text { BRAVA }\end{array}$} & \multirow[t]{2}{*}{ Study name } & & & \multicolumn{5}{|c|}{ Mean and $95 \% \mathrm{Cl}$} \\
\hline & & $\begin{array}{l}\text { Lower } \\
\text { limit }\end{array}$ & $\begin{array}{l}\text { Upper } \\
\text { limit }\end{array}$ & & & & & \\
\hline BRAVA(-) & 50.290 & 45.006 & 55.574 & | & | & & & \\
\hline BRAVA(+) & 66.262 & 58.852 & 73.672 & & & & & \\
\hline \multirow[t]{2}{*}{ Overall } & 55.674 & 51.372 & 59.977 & & & & & \\
\hline & & & & -80.00 & -40.00 & 0.00 & 40.00 & 80.00 \\
\hline
\end{tabular}

Pooled estimates in breast recipient

Fig. 5. Subgroup analysis according to whether the BRAVA device was used. Pooled estimates of fat survival rates for the BRAVA device group and non-BRAVA device group among breast recipients $(\mathrm{P}<0.001) . \mathrm{Cl}$, confidence interval. 
was no significant difference between the CAL and NCAL group. Similarly, no significant difference was found according to the purpose, harvesting method, or refinement method. However, a significantly higher survival rate was observed when the breast was preexpanded using the BRAVA device before fat grafting (66.2\%; $95 \%$ CI, $58.9-73.7 \%$ vs. 50.3\%; 95\% CI, 45.0-55.6\%; P<0.001) (Fig. 5).

\section{DISCUSSION}

This meta-analysis investigated the fat graft survival rate and the factors that affected the survival rate of fat grafts. The 27 studies evaluated showed a mean survival rate of $56 \%$. A subgroup analysis was performed to analyze the factors affecting the survival rate and to identify the patient groups that showed the highest survival rates.

Adequate neovascularization is essential for fat survival. Problems that occur during this process are among the mechanisms that reduce the survival rate. CAL is a solution to this problem. Supplementation of the fat graft with ASCs during CAL is expected to improve the fat graft survival rate through the following mechanisms [28]: 1) differentiation into adipocytes and regeneration of adipose tissue; 2) differentiation into endothelial cells and promotion of angiogenesis; 3) release of growth factors and other factors that help the surrounding tissue resist hypoxia and ischemia; and 4) survival of original ASCs. By pooling data from previous clinical studies, we found that CAL resulted in higher survival rates than NCAL, especially in the face; however, additional research is needed to understand the exact mechanism behind this observation.

All else being equal, a small graft volume placed in a large recipient will have a higher percentage survival than a large graft volume placed in a small recipient [29]. Therefore, use of the BRAVA external breast expander before fat grafting has been reported to increase the survival rate, as the device can increase tissue compliance, increase the potential recipient space, and create an abundant stromal scaffold. In this study, pre-expansion using the BRAVA device significantly increased the survival rate of fat grafts.

Several meta-analyses related to fat grafts have been conducted in the past. Zhou et al. [30] performed a meta-analysis of the efficacy and safety of CAL. However, they simply assessed the event rate of gains in volume relative to the injection volume instead of the fat graft survival rate in the data coding process. This meant that the SDs between different studies and sample sizes were not considered, and studies involving breasts with a larger injection volume had a greater influence on the analysis of the overall survival rate than studies involving the face, which had a relatively smaller weighted value of injections. Just as this study considered the fat graft survival rate as continuous rather than categorical data, comparisons should be made by calculating the mean effect size based on the mean values, $\mathrm{SD}$, and sample size.

Wang and $\mathrm{Wu}$ [31] also performed a meta-analysis of case-control studies evaluating the efficacy of CAL, but their subgroup anal- ysis was only based on patient satisfaction results. Krastev et al. [32] performed a meta-analysis of facial fat grafting. The survival rates at various facial sites were presented, but the remaining subgroup analyses were based on patient satisfaction results.

As demonstrated by the findings in the present study, the values reported for the survival rate of fat grafts showed a heterogeneity of $>90 \%$, even with a moderator analysis, indicating that there was a significant level of heterogeneity. This may be attributable to the fact that there is no standardized method for fat grafting; therefore, heterogeneity in the results was inevitable. Moreover, although publication bias existed, the fail-safe $\mathrm{N}$ confirmed the reliability of the results of this study. This study is the first meta-analysis to objectively evaluate the survival rate of fat grafts using a medical device, and to analyze the patient and procedural factors that affected the survival rate. However, in the process of efficacy evaluation based on patient satisfaction and the mean number of procedures performed, patients who underwent a procedure only once based on the surgeon's arbitrary decision, or who underwent a predetermined number of procedures, were excluded from the analysis. Furthermore, during the process of the literature search and selection, only studies related to fat survival rates were included. Safety was not evaluated, because our selection process may have missed articles with information relevant to safety. Finally, studies had different follow-up periods and times when the fat graft survival rate was assessed. As it has been reported that the survival rate generally does not significantly change after 3 months [33-38], our analysis was conducted on survival rates measured at 3 months or longer. Therefore, large-scale, randomized controlled trials with longer followup periods that overcome these limitations are needed. Such trials must not only analyze patient- and procedure-associated factors, but should also perform a multifaceted analysis of efficacy and safety.

\section{REFERENCES}

1. Khouri RK Jr, Khouri RK. Current clinical applications of fat grafting. Plast Reconstr Surg 2017;140:466e-86e.

2. Stasch T, Hoehne J, Huynh T, et al. Debridement and autologous lipotransfer for chronic ulceration of the diabetic foot and lower limb improves wound healing. Plast Reconstr Surg 2015;136:1357-66.

3. Marangi GF, Pallara T, Cagli B, et al. Treatment of early-stage pressure ulcers by using autologous adipose tissue grafts. Plast Surg Int 2014; 2014:817283.

4. Gutiérrez Santamaría J, Masiá Gridilla J, Pamias Romero J, et al. Fat grafting is a feasible technique for the sequelae of head and neck cancer treatment. J Craniomaxillofac Surg 2017;45:93-8.

5. Coleman SR. Structural fat grafts: the ideal filler? Clin Plast Surg 2001; 28:111-9.

6. Tiryaki T, Findikli N, Tiryaki D. Staged stem cell-enriched tissue (SET) injections for soft tissue augmentation in hostile recipient areas: a preliminary report. Aesthetic Plast Surg 2011;35:965-71. 
7. Coleman SR. Facial recontouring with lipostructure. Clin Plast Surg 1997;24:347-67.

8. Fontdevila J, Serra-Renom JM, Raigosa M, et al. Assessing the longterm viability of facial fat grafts: an objective measure using computed tomography. Aesthet Surg J 2008;28:380-6.

9. Gonzalez AM, Lobocki C, Kelly CP, et al. An alternative method for harvest and processing fat grafts: an in vitro study of cell viability and survival. Plast Reconstr Surg 2007;120:285-94.

10. Matsumoto D, Sato K, Gonda K, et al. Cell-assisted lipotransfer: supportive use of human adipose-derived cells for soft tissue augmentation with lipoinjection. Tissue Eng 2006;12:3375-82.

11. Yoshimura K, Sato K, Aoi N, et al. Cell-assisted lipotransfer for cosmetic breast augmentation: supportive use of adipose-derived stem/ stromal cells. Aesthetic Plast Surg 2008;32:48-55; discussion 6-7.

12. Thorne CH, Beasley RW, Aston SJ, et al., editors. Grabb and Smith's plastic surgery. 6th ed. Philadelphia, PA: Lippincott Williams \& Wilkins; 2007.

13. Gentile P, De Angelis B, Pasin M, et al. Adipose-derived stromal vascular fraction cells and platelet-rich plasma: basic and clinical evaluation for cell-based therapies in patients with scars on the face. J Craniofac Surg 2014;25:267-72.

14. Del Vecchio D, Rohrich RJ. A classification of clinical fat grafting: different problems, different solutions. Plast Reconstr Surg 2012;130:51122.

15. Rieck B, Schlaak S. Measurement in vivo of the survival rate in autologous adipocyte transplantation. Plast Reconstr Surg 2003;111:2315-23.

16. Phulpin B, Gangloff P, Tran N, et al. Rehabilitation of irradiated head and neck tissues by autologous fat transplantation. Plast Reconstr Surg 2009;123:1187-97.

17. Salgarello M, Visconti G, Farallo E. Autologous fat graft in radiated tissue prior to alloplastic reconstruction of the breast: report of two cases. Aesthetic Plast Surg 2010;34:5-10.

18. Panettiere P, Marchetti L, Accorsi D. The serial free fat transfer in irradiated prosthetic breast reconstructions. Aesthetic Plast Surg 2009;33: 695-700.

19. Panettiere P, Accorsi D, Marchetti L, et al. Large-breast reconstruction using fat graft only after prosthetic reconstruction failure. Aesthetic Plast Surg 2011;35:703-8.

20. Slack GC, Tabit CJ, Allam KA, et al. Parry-Romberg reconstruction: beneficial results despite poorer fat take. Ann Plast Surg 2014;73:30710.

21. Rohrich RJ, Sorokin ES, Brown SA. In search of improved fat transfer viability: a quantitative analysis of the role of centrifugation and harvest site. Plast Reconstr Surg 2004;113:391-5; discussion 6-7.

22. Condé-Green A, de Amorim NF, Pitanguy I. Influence of decantation, washing and centrifugation on adipocyte and mesenchymal stem cell content of aspirated adipose tissue: a comparative study. J Plast Reconstr Aesthet Surg 2010;63:1375-81.

23. Khouri RK, Khouri RK Jr, Rigotti G, et al. Aesthetic applications of Brava-assisted megavolume fat grafting to the breasts: a 9-year, 476-pa- tient, multicenter experience. Plast Reconstr Surg 2014;133:796-807; discussion 8-9.

24. Moher D, Shamseer L, Clarke M, et al. Preferred reporting items for systematic review and meta-analysis protocols (PRISMA-P) 2015 statement. Syst Rev 2015;4:1.

25. OCEBM Levels of Evidence Working Group. The Oxford 2011 levels of evidence [Internet]. Oxford, UK: Oxford Centre for Evidence-Based Medicine; c2011 [cited 2014 Sep 21]. Available from http://www.cebm. net/ocebm-levels-of-evidence/.

26. Higgins JP, Thompson SG, Deeks JJ, et al. Measuring inconsistency in meta-analyses. BMJ 2003;327:557-60.

27. Higgins JPT, Green S. Cochrane Handbook for systematic reviews of interventions version 5.1.0 [Internet]. London, UK: The Cochrane Collaboration; c2011 [cited 2018 Jan 1]. Available from www.handbook.cochrane.org.

28. Yoshimura K, Suga H, Eto H. Adipose-derived stem/progenitor cells: roles in adipose tissue remodeling and potential use for soft tissue augmentation. Regen Med 2009;4:265-73.

29. Khouri RK, Rigotti G, Cardoso E, et al. Megavolume autologous fat transfer: part I. Theory and principles. Plast Reconstr Surg 2014;133: 550-7.

30. Zhou Y, Wang J, Li H, et al. Efficacy and safety of cell-assisted lipotransfer: a systematic review and meta-analysis. Plast Reconstr Surg 2016; 137:44e-57e.

31. Wang Y, Wu Y. Assessment of the clinical efficacy of cell-assisted lipotransfer and conventional fat graft: a meta-analysis based on case-control studies. J Orthop Surg Res 2017;12:155.

32. Krastev TK, Beugels J, Hommes J, et al. Efficacy and safety of autologous fat transfer in facial reconstructive surgery: a systematic review and meta-analysis. JAMA Facial Plast Surg 2018;20:351-60.

33. Wang L, Luo X, Lu Y, et al. Is the resorption of grafted fat reduced in cell-assisted lipotransfer for breast augmentation? Ann Plast Surg 2015; 75:128-34.

34. Sasaki GH. The safety and efficacy of cell-assisted fat grafting to traditional fat grafting in the anterior mid-face: an indirect assessment by 3D imaging. Aesthetic Plast Surg 2015;39:833-46.

35. Chang Q, Li J, Dong Z, et al. Quantitative volumetric analysis of progressive hemifacial atrophy corrected using stromal vascular fractionsupplemented autologous fat grafts. Dermatol Surg 2013;39:1465-73.

36. Schendel SA. Enriched autologous facial fat grafts in aesthetic surgery: 3D volumetric results. Aesthet Surg J 2015;35:913-9.

37. Dos Anjos S, Matas-Palau A, Mercader J, et al. Reproducible volume restoration and efficient long-term volume retention after point-ofcare standardized cell-enhanced fat grafting in breast surgery. Plast Reconstr Surg Glob Open 2015;3:e547.

38. Gentile P, Orlandi A, Scioli MG, et al. A comparative translational study: the combined use of enhanced stromal vascular fraction and plateletrich plasma improves fat grafting maintenance in breast reconstruction. Stem Cells Transl Med 2012;1:341-51.

39. Yoshimura K, Asano Y, Aoi N, et al. Progenitor-enriched adipose tis- 
sue transplantation as rescue for breast implant complications. Breast J 2010;16:169-75.

40. Gontijo-de-Amorim NF, Charles-de-Sá L, Rigotti G. Mechanical supplementation with the stromal vascular fraction yields improved volume retention in facial lipotransfer: a 1-year comparative study. Aesthet Surg J 2017;37:975-85.

41. Tissiani LA, Alonso N. A prospective and controlled clinical trial on stromal vascular fraction enriched fat grafts in secondary breast reconstruction. Stem Cells Int 2016;2016:2636454.

42. Gentile P, Scioli MG, Orlandi A, et al. Breast reconstruction with enhanced stromal vascular fraction fat grafting: what is the best method? Plast Reconstr Surg Glob Open 2015;3:e406.

43. Tanikawa DY, Aguena M, Bueno DF, et al. Fat grafts supplemented with adipose-derived stromal cells in the rehabilitation of patients with craniofacial microsomia. Plast Reconstr Surg 2013;132:141-52.

44. Peltoniemi HH, Salmi A, Miettinen S, et al. Stem cell enrichment does not warrant a higher graft survival in lipofilling of the breast: a prospective comparative study. J Plast Reconstr Aesthet Surg 2013;66:1494-503.

45. Li J, Gao J, Cha P, et al. Supplementing fat grafts with adipose stromal cells for cosmetic facial contouring. Dermatol Surg 2013;39:449-56.

46. Kølle SF, Fischer-Nielsen A, Mathiasen AB, et al. Enrichment of autologous fat grafts with ex-vivo expanded adipose tissue-derived stem cells for graft survival: a randomised placebo-controlled trial. Lancet 2013;382:1113-20.

47. Koh KS, Oh TS, Kim H, et al. Clinical application of human adipose tissue-derived mesenchymal stem cells in progressive hemifacial atrophy (Parry-Romberg disease) with microfat grafting techniques using 3-dimensional computed tomography and 3-dimensional camera. Ann Plast Surg 2012;69:331-7.

48. Sommeling CE, Van Landuyt K, Depypere H, et al. Composite breast reconstruction: implant-based breast reconstruction with adjunctive lipofilling. J Plast Reconstr Aesthet Surg 2017;70:1051-8.

49. Denadai R, Raposo-Amaral CA, Pinho AS, et al. Predictors of autologous free fat graft retention in the management of craniofacial contour deformities. Plast Reconstr Surg 2017;140:50e-61e.

50. Zhu M, Xie Y, Zhu Y, et al. A novel noninvasive three-dimensional volumetric analysis for fat-graft survival in facial recontouring using the $3 \mathrm{~L}$ and 3M technique. J Plast Reconstr Aesthet Surg 2016;69:24854.

51. Yang $\mathrm{X}, \mathrm{Wu} \mathrm{R}, \mathrm{Bi} \mathrm{H}$, et al. Autologous fat grafting with combined threedimensional and mirror-image analyses for progressive hemifacial atrophy. Ann Plast Surg 2016;77:308-13.

52. Stillaert FB, Sommeling C, D’Arpa S, et al. Intratissular expansion-mediated, serial fat grafting: a step-by-step working algorithm to achieve $3 \mathrm{D}$ biological harmony in autologous breast reconstruction. J Plast Reconstr Aesthet Surg 2016;69:1579-87.

53. Sforza M, Andjelkov K, Zaccheddu R, et al. A preliminary assessment of the predictability of fat grafting to correct silicone breast implantrelated complications. Aesthet Surg J 2016;36:886-94.

54. Jiang T, Xie Y, Zhu M, et al. The second fat graft has significantly better outcome than the first fat graft for Romberg syndrome: a study of three-dimensional volumetric analysis. J Plast Reconstr Aesthet Surg 2016;69:1621-6.

55. Uda H, Tomioka YK, Sugawara Y, et al. Shaping of the unaffected breast with brava-assisted autologous fat grafting to obtain symmetry after breast reconstruction. Aesthet Surg J 2015;35:565-73.

56. Gerth DJ, King B, Rabach L, et al. Long-term volumetric retention of autologous fat grafting processed with closed-membrane filtration. Aesthet Surg J 2014;34:985-94.

57. Guibert M, Franchi G, Ansari E, et al. Fat graft transfer in children's facial malformations: a prospective three-dimensional evaluation. J Plast Reconstr Aesthet Surg 2013;66:799-804.

58. Khouri RK, Eisenmann-Klein M, Cardoso E, et al. Brava and autologous fat transfer is a safe and effective breast augmentation alternative: results of a 6-year, 81-patient, prospective multicenter study. Plast Reconstr Surg 2012;129:1173-87.

59. Del Vecchio DA, Bucky LP. Breast augmentation using preexpansion and autologous fat transplantation: a clinical radiographic study. Plast Reconstr Surg 2011;127:2441-50.

60. Meier JD, Glasgold RA, Glasgold MJ. Autologous fat grafting: longterm evidence of its efficacy in midfacial rejuvenation. Arch Facial Plast Surg 2009;11:24-8.

61. Zocchi ML, Zuliani F. Bicompartmental breast lipostructuring. Aesthetic Plast Surg 2008;32:313-28.

62. Ho Quoc C, Taupin T, Guerin N, et al. Volumetric evaluation of fat resorption after breast lipofilling. Ann Chir Plast Esthet 2015;60:495-9.

63. Spear SL, Pittman T. A prospective study on lipoaugmentation of the breast. Aesthet Surg J 2014;34:400-8.

64. Small K, Choi M, Petruolo O, et al. Is there an ideal donor site of fat for secondary breast reconstruction? Aesthet Surg J 2014;34:545-50.

65. Choi M, Small K, Levovitz C, et al. The volumetric analysis of fat graft survival in breast reconstruction. Plast Reconstr Surg 2013;131:185-91.

66. Beck M, Amar O, Bodin F, et al. Evaluation of breast lipofilling after sequelae of conservative treatment for cancer: a prospective study of ten cases. Eur J Plast Surg 2012;35:221-8.

67. Tanna N, Wan DC, Kawamoto HK, et al. Craniofacial microsomia soft-tissue reconstruction comparison: inframammary extended circumflex scapular flap versus serial fat grafting. Plast Reconstr Surg 2011;127:802-11.

68. Amar O, Bruant-Rodier C, Lehmann S, et al. Fat tissue transplant: restoration of the mammary volume after conservative treatment of breast cancers, clinical and radiological considerations. Ann Chir Plast Esthet 2008;53:169-77. 